\title{
Inclusão digital e educação para a competência informacional: uma questão de ética e cidadania*
}

\author{
Helena Silva \\ Doutora em engenharia de produção (UFSC), mestre \\ em ciência da informação (Ibict/UFRJ), \\ Professor adjunto do Instituto de Ciência da Informação, UFBA. \\ E-mail: helenaps@ufba.br \\ Othon Jambeiro \\ $\mathrm{PhD}$ em estudos da comunicação (University of Westminster, U.K), \\ mestre em ciências sociais (USP). Professor titular do Instituto \\ de Ciência da Informação (UFBA). Pesquisador 1-C do CNPq. \\ E-mail: othon@ufba.br \\ Jussara Lima \\ Especialista em gestão estratégica empresarial (Universidade \\ de Passo Fundo), mestranda em ciência da informação \\ do Instituto de Ciência da Informação (UFBA). \\ E-mail: ussaraborges2003@yahoo.com.br \\ Marco Antônio Brandão \\ Especialista em metodologia do ensino, pesquisa e extensão \\ (Uneb) e em terapia de família (UCam). Mestrando em ciência \\ da informação do Instituto de Ciência da Informação (UFBA). \\ E-mail: marcobrandao@zipmail.com.br
}

\section{Resumo}

Este artigo é o resultado de um esforço para conceituar inclusão digital, feito pelo Grupo de Estudos em Políticas de Informação e Inclusão Digital (Gepindi), vinculado ao Programa de Pós-graduação em Ciência da Informação, do Instituto de ciência da Informação, da Universidade Federal da Bahia (Posici/ICI/UFBA). O texto discute inclusão digital à luz de outros conceitos encontrados na ciência da informação e em áreas correlatas. No imbricado entrelaçamento desses conceitos complexos, o resultado final pretendido é um marco de compreensão para a vinculação entre ética e cidadania, de um lado, e educação para a informação na Internet ou information literacy education, de outro, com vistas à inclusão social.

\section{Palavras-chave}

Inclusão digital; Competência informacional; Letramento informacional; Educação para a competência informacional; Cidadania; Ética.

\section{Digital Inclusion and Information Literacy Education: a Matter for Ethics and Citizenship}

\begin{abstract}
This paper tries to conceptualize digital inclusion. It results from an internal discussion in the Gepindi (Study Group on Information Policies and Digital Inclusion), which is linked to the Graduate Program of Information Science, at the Federal University of Bahia, Brazil. The paper discusses digital inclusion based on information science and correlate areas concepts. Its aim is to construct a knowledge landmark on the relationship between ethics, citizenship and information literacy education, as a basic pillar for social inclusion.
\end{abstract}

\section{Keywords}

Digital inclusion; Information literacy; Information literacy education; Citizenship; Ethics.

\section{INTRODUÇÃO}

Este artigo representa o resultado de um esforço empreendido para conceituar inclusão digital pelo Grupo de Estudos em Políticas de Informação e Inclusão Digital (Gepindi) $^{* *}$, que é vinculado ao Programa de Pós-graduação em Ciência da Informação, do Instituto de Ciência da Informação, da Universidade Federal da Bahia (Posici/ ICI/UFBA) $)^{* * *}$.

O tema inclusão digital e acesso à informação, uma das linhas internas de pesquisa do Gepindi, passou a fazer parte do objeto de investigação do Grupo a partir do Programa de Cooperação Capes/Universidade do Texas, que envolve o ICI e a Faculdade de Comunicação da UFBA, por meio do qual se realiza o projeto Infra-estruturas e Serviços de Informação e Comunicação, no Brasil e Estados Unidos: Regulação, Acesso, Conteúdos e Tecnologias na Sociedade da Informação em Austin e Salvador. O objetivo é a realização de estudos, desenvolvidos em subprojetos, nas duas cidades, sobre temas relacionados aos serviços e tecnologias de informação e comunicação (TICs), entre eles políticas e ações de inclusão digital. Posteriormente, serão feitas pesquisas comparativas sobre a realidade dessas cidades.

Como subprojeto desse projeto maior, foi concebida e está sendo desenvolvida, no âmbito do Gepindi, a investigação: "Informação na internet e inclusão digital: estudo nas organizações que trabalham na perspectiva da inclusão digital, na cidade de Salvador-BA (Infoinclusão)". O objetivo é verificar se organizações que promovem ações denominadas por elas de inclusão digital prevêem nas suas políticas e incluem nas suas práticas o acesso a determinadas informações disponíveis na Internet, em particular as de cunho utilitário e contextual, ou seja, que, de alguma forma, contribuam para a melhoria da qualidade de vida do "incluído digitalmente".

Os conceitos de informação utilitária e contextual adotados pelo Infoinclusão estão de acordo com Barreto

\footnotetext{
*Este artigo é um produto do projeto de pesquisa Informação na Internet e Inclusão Digital: estudo nas organizações que trabalham da perspectiva da inclusão digital na cidade de Salvador/BA, que foi contemplado com auxílio financeiro pelo Edital Universal CNPq 01/2002.

${ }^{* *}$ http://www.posici.ufba.br/gepindi.html

${ }^{* * *}$ http://www.posici.ufba.br
} 
(1994), que classifica a informação traçando um paralelo com a pirâmide de Maslow. Informação utilitária é aquela utilizada para suprir necessidades básicas de indivíduos ou grupos. Caracteriza-se por responder questões relacionadas à alimentação, habitação, vestuário, saúde, educação etc. A informação contextual é aquela requisitada por indivíduos ou grupos que buscam esse tipo de informação como garantia de permanência para os diversos contextos dos quais participam - profissional, comunidade etc.

Ganha atenção especial, no subprojeto, o crescente esforço do governo federal para o estabelecimento do chamado governo eletrônico, com desenvolvimento e consolidação vinculados, no discurso oficial, à universalização da inclusão digital. Sem "cidadãos digitais", não há "governo eletrônico". Dessa premissa, busca-se saber se as propostas governamentais e seus condicionantes sociais são de conhecimento das organizações devotadas à inclusão digital e se elas utilizam as informações disponibilizadas no portal do governo.

Pelo crescente envolvimento de diferentes atores nesse tema, sobretudo governos dos três níveis de poder e organizações sociais de vários tipos, tem-se que inclusão digital é um assunto aberto à investigação e de grande interesse social e econômico. Sua assunção como linha de pesquisa do Gepindi responde, portanto, ao significado que o tema passou a representar para a sociedade, à consolidação da democracia e à inclusão social de indivíduos e grupos tradicionalmente excluídos do desenvolvimento socioeconômico.

Contudo, o conceito de inclusão digital não está ainda bem estabelecido. Isso levou o Gepindi a considerar como questão primordial discuti-lo à luz de outros conceitos encontrados na ciência da informação e em áreas correlatas. Este texto é resultado do debate interno entre pesquisadores, por meio do qual se formulou um quadro de referência conceitual sobre o tema que deve pautar as pesquisas do grupo no que concerne à inclusão digital.

\section{CONCEITO VERSUS CONTEXTO}

Desde o início das discussões, ficou claro que inclusão digital deve expressar um conceito que encerre uma consideração profundamente humanista. $O$ mundo contemporâneo está em um estado de transformações e as possibilidades de deterioração das relações humanas tornam-se tão presentes, que o resgate de certos valores "meio adormecidos", no afã do desenvolvimento puramente tecnológico e econômico, precisa ser considerado.

$\mathrm{Na}$ tarefa de busca do fundamento teórico - em fascinante exercício intelectual -, o grupo deparou-se com uma profusão de conceitos, alguns emergentes e outros clássicos e milenares, que, por caminhos diversos, convergem para um conceito de inclusão digital como novo ethos ético e sociopolítico. Ele está, irrecusavelmente, inserido no "espírito do nosso tempo", isto é, constitui-se como fruto do que se denomina sociedade da informação, baseada nas redes digitais, ou sociedade do conhecimento, que privilegia o saber perante o fazer. Ambas as denominações são unificadas pelo condicionamento do sucesso pessoal e social à aprendizagem contínua, em uma conformação de círculo virtuoso e, por conseqüência, de uma educação global.

O conceito de ethos, já utilizado pelos gregos antigos, como Homero e Aristóteles, de acordo com Lastoria (2001, p.63), significava a morada do homem, isto é, a natureza. Uma vez processada mediante a ação humana, sob a forma de cultura, ela faz com que a regularidade própria aos fenômenos naturais seja transposta para a dimensão dos costumes de uma determinada sociedade. A cultura promove, então, a sua própria ordenação, ao estabelecer normas e regras de conduta, que devem ser observadas por todos os seus membros.

Ainda de acordo com Lastoria (2001, p.63), os gregos compreendiam que o ethos é, para o homem, a expressão normativa da sua própria natureza. Embora uma criação humana, a expressão normativa pode ser observada a partir de um distanciamento consciente, quando, então, adentra-se o terreno da ética, como discurso racional sobre o ethos.

Segundo Caniello (2003, p.31-32), o conceito de ethos, apropriado pelas ciências sociais por Kroeber e Geertz, tem estreita identidade com a noção de Volksgeist (espírito de um povo), elemento central da filosofia de Hegel, para quem o "espírito de um povo ou cultura, estará sempre traspassado pelo "espírito do tempo" (Zeitgeist), que lhe impõe limitações e constrangimentos.

Na síntese de Caniello (2003, p.32) sobre o pensamento de Kroeber e Geertz, o ethos guarda a marca da estrutura que conforma a tradição de um povo, seu "espírito", mas também comporta os influxos da ação dos sujeitos e das pressões conjunturais que interagem com essa estrutura, em determinado tempo histórico.

Pires (2001, p.3; 14), discorrendo sobre globalização, entende ethos como uma consciência ética universal (em alemão:Weltethos). Significa a atitude moral básica do homem, considerado individual ou coletivamente. Para o autor, o ethos universal deve ser constituído por meio da luta pela preservação da Declaração dos Direitos Humanos da Organização das Nações Unidas (ONU) e por uma globalização solidária, em escala planetária. 


\section{Helena Silva / Othon Jambeiro / Jussara Lima / Marco Antônio Brandão}

Tem-se, então, como fundamental, que a inclusão digital deve ser vista sob o ponto de vista ético, sendo considerada como uma ação que promoverá a conquista da "cidadania digital" e contribuirá para uma sociedade mais igualitária, com a expectativa da inclusão social. É possível, portanto, formular uma base conceitual para inclusão digital, com fundamento no espírito de ética universal.

Dado que inclusão digital é parte do fenômeno informação, no contexto da chamada sociedade da informação, pode ser observada pela ótica da ciência da informação. Neste sentido, entende-se, como ponto de partida do conceito de inclusão digital, o acesso à informação que está nos meios digitais e, como ponto de chegada, a assimilação da informação e sua reelaboração em novo conhecimento, tendo como conseqüência desejável a melhoria da qualidade de vida das pessoas.

No imbricado entrelaçamento de conceitos complexos, o resultado final pretendido por este texto é um marco de compreensão para a vinculação entre ética e cidadania, de um lado, e educação para a informação por via digital, de outro, com vistas à inclusão social. É isto que será discutido nos itens seguintes. Sem a preocupação de ser exaustivo, procura-se chegar a uma "conceituação necessária", no sentido de entendimento da imbricação dos conceitos que devem expressar inclusão digital.

\section{ÉTICA E CIDADANIA NO ETHOS CONTEMPORÂNEO}

O aprofundamento no conceito de ética, que tem extensa e complexa formação filosófica, não é objeto de estudo aqui. $O$ mesmo se aplica ao conceito de cidadania. A idéia é relacionar esses dois conceitos, como base para a conceituação de inclusão digital, o que nos parece fundamental.

Para iniciar as reflexões sobre ética e cidadania são oportunas as observações de Hack (2002, p.7) e de Gouvêa (2002, p.10). O primeiro relembra que a ética provoca a reflexão de idéias e propõe valores; a cidadania conduz à prática social responsável e o envolvimento solidário. Para o segundo, ao termo 'ética', desde a Grécia, sempre foi utilizado por aqueles que se dispunham a investigar as questões referentes ao comportamento humano e à vida em sociedade.

Cidadania, de acordo com o pensamento de Bodstein (1997), apesar de sua estreita relação com a ideologia individualista moderna, deve ser abordada como uma experiência histórica, cujo aparecimento remete à Antigüidade Grega. Desde o seu início, caracteriza uma relação entre iguais, e destes com o poder. Assim, só ganha existência como medida de igualdade e de convivência coletiva dentro de uma comunidade política, composta de sujeitos portadores de direitos.

Constitui-se, dessa forma, em pré-requisito indispensável para inclusão e participação na vida pública. É inseparável da noção de igualdade sociopolítica, presente de forma restrita ou ampliada em todas as sociedades. De qualquer maneira e em suas múltiplas dimensões, a cidadania é um meio de proteção e uma condição para o exercício dos direitos e, também, deveres.

Portanto, para estudar e conceituar inclusão digital - um dos principais temas e problemas sociais da sociedade contemporânea - são fundamentais, ainda que de forma abrangente, as considerações sobre ética e cidadania, com a visão do momento atual, do Zeitgeist. Reforçando a idéia da mudança do conceito de ética de acordo com a época, Souza Neto e De Liberal (2002, p.31) colocam que a ética não é dada, mas construída no cerne das relações humanas e sociais. À medida que essas relações se modificam, também se alteram o sentido e o conteúdo da ética.

Também para Frade (2002, p.1), o conceito de cidadania é mutável desde os primórdios da sociedade organizada. Porém, nas últimas décadas, essa variação se acelerou em ritmos alucinantes, adequando-se às novas exigências do mundo contemporâneo. A intensificação e ampliação da globalização da política, da economia, da quebra de fronteiras na disseminação de culturas, a explosão e mercantilização da informação condicionaram o exercício da cidadania plena ao alcance de novos patamares de riqueza, educação e acesso a serviços e produtos.

O trabalho de Gouvêa (2002, p.9), cujo título expressa o sentido da abordagem que se quer dar neste artigo - ética e cidadania: a busca humana por valores solidários -, ressalta a importância das considerações acerca das grandes transformações que estamos vivenciando, particularmente em função do avanço acelerado das TICs, que permitem o fluxo veloz da informação, com conseqüências ainda imprevisíveis.

Dessa maneira, para garantir justiça social no mundo do século XXI, Dyson (2001), citado por Ronca e Costa (2002, p.29), remete à necessidade de colocar as tecnologias a serviço da ética, à responsabilidade da política nas aplicações das ferramentas desenvolvidas pela ciência e às dificuldades e soluções para unir tecnologias e seres humanos em prol de uma vida mais digna para todos.

Para contribuir na solução do dilema democrático, Frade (2002, p.13) adverte que um novo modelo de cidadania 
Inclusão digital e educação para a competência informacional: uma questão de ética e cidadania

deve ir além da esfera da informação, incorporando a capacidade de interpretação da realidade e construção de sentido por parte dos indivíduos. $\mathrm{O}$ que importa na formação dos cidadãos, sob essa perspectiva, é que sejam capazes de ser construtores de significados. Nessa mesma linha de pensamento, Rocha (2000) também discorre sobre a questão da cidadania na sociedade da informação como um processo de conscientização do indivíduo, por meio da educação e acesso à informação e ao conhecimento (grifo nosso).

Demo, citado por Silveira (2000, p.85), define cidadania como "a raiz dos direitos humanos", sendo a falta de cidadania suprida pela tutela e assistência exercida pelo Estado sobre os cidadãos. Cabe ao Estado prover - ou viabilizar que outros o façam - o acesso à informação, e não apenas mediar as relações entre os homens, privilegiando a estrutura de poder, pois a informação é mais que a mercadoria por excelência da sociedade pós-industrial: é a sua própria razão de ser. Ela condiciona a existência da sociedade e sua coerência. A informação é um produto e um bem social (SILVEIRA, 2000, p.85).

Em concordância com esse posicionamento, Araújo (1999) considera que a construção da cidadania, ou de práticas de cidadania, passa, necessariamente, pela questão do acesso e uso de informação. Tanto a conquista de direitos políticos, civis e sociais, quanto a implementação dos deveres do cidadão dependem do livre acesso à informação sobre tais direitos e deveres. Ou seja, dependem da ampla disseminação e circulação da informação e, ainda, de um processo comunicativo de discussão crítica sobre as diferentes questões relativas à construção de uma sociedade mais justa e, portanto, com maiores oportunidades para todos os cidadãos.

Já em 19977, Miranda, citado por Silveira (2000, p.85), afirmava que os países em desenvolvimento precisavam "acelerar a disseminação da informação em todos os níveis de sua estrutura social". Essa é a questão central: assegurar o acesso à informação, para a construção de uma cidadania plena, a cidadania ativa, como coloca Bobbio (1986), lembrando Norbert Wiener: "Ser informado é ser livre".

Em síntese, em tempos de profundas mudanças e de desigualdades ampliadas pela exclusão digital, é fundamental estudar a vida em sociedade, tendo a ética como um dos requisitos do cidadão. É também uma questão de vontade política, da qual todos devem munir-se, visando a possibilitar a inclusão digital e, assim, permitir a conquista da cidadania pelos indivíduos ainda dela excluídos.

A importância das considerações sobre ética e cidadania está, nos dias atuais, no sentido de se buscar compreender sua estreita vinculação com o sentido de solidariedade, como destacam Souza Neto e Liberal (2002, p.34). Por conseqüência, garantir o acesso à informação na sociedade atual é um problema cuja solução deve levar em conta abordagens que busquem valores fundamentais e universais, que parecem esquecidos em uma sociedade tão racionalizada.

Esses valores passam pelo reconhecimento da cidadania como base para a atuação do homem na sociedade. $\mathrm{Na}$ busca por esse conceito, o pensamento de Gouvêa (2002, p.10) expressa de forma fiel as discussões do Gepindi e o sentimento do grupo sobre essa necessidade de revisão de valores e sobre a formação do cidadão no século XXI, seus direitos e deveres. São tão apropriadas as suas observações, que se decidiu transcrevê-las:

A sociedade tecnológica é filha da ciência moderna e da aplicação sistemática do método científico indutivo. Isto, por um lado, comprova o sucesso inquestionável da ciência moderna, que nos deu este admirável mundo novo. Por outro lado, aponta para um fato até agora reconhecido por poucos, mas cada vez mais evidente: a ciência não possui respostas para os problemas éticos e sociais que cria. Pior que isso, a ciência é, por sua própria natureza, intrinsecamente incapaz de satisfazer essa necessidade e, conseqüentemente, ao tentar fazê-lo, deixa de ser mera ciência. É preciso, portanto, buscar o auxílio de outro tipo de pensadores: filósofos, poetas, teólogos, artistas, antropólogos, psicanalistas, gente envolvida em estudos humanísticos e socioculturais, políticos, juristas, economistas, sábios e adivinhos. Toda ajuda é bem-vinda nesse empenho multidisciplinar pela busca de valores sociais universais, uma busca hoje que, longe de ser supérflua, é indispensável para o futuro da espécie humana e para o nosso bem-estar.

Quanto à formação de um cidadão, Gouvêa (2002, p.11) questiona sobre aos direitos:

Há quem pense que basta nascer para ser um cidadão. Esta é uma meia verdade. Por um lado, tornou-se uma verdade universalmente aceita que todas as pessoas possuem certos direitos naturais inalienáveis. Por outro lado, podemos perguntar se estes direitos "inalienáveis" não dependem, para que sejam de fato inalienáveis, de que sejam reconhecidos pela autoridade vigente como tais em relação ao indivíduo em questão. Em outras palavras, é possível que exista um indivíduo que vive em uma sociedade na qual não possui 
todos os direitos de um cidadão típico. Numa sociedade escravagista, por exemplo, um escravo é um indivíduo que vive naquela sociedade sem possuir direitos básicos de cidadania. Nos tempos do Império Romano, para dar outro exemplo, havia moradores livres do império que não possuíam, no entanto, direitos fundamentais de cidadania. Esta reflexão nos remete a uma série de perguntas. Por exemplo, podemos nos perguntar se há, em nossa sociedade, pessoas cujos direitos de cidadania não são de fato reconhecidos, ou, o que dá no mesmo, são reconhecidos 'de direito', mas não 'de fato'.

Imediatamente após o questionamento sobre os direitos, Gouvêa reflete sobre os deveres:

Outra pergunta importante a que esta reflexão nos remete tem a ver não com direitos, mas sim com os deveres dos cidadãos. Em suma, é questionável se o indivíduo que, tendo reconhecidos seus plenos direitos de cidadão, não assume em contrapartida seus deveres de cidadão é, de fato, um cidadão no mais pleno sentido da palavra. No mínimo, seria necessário reconhecer sua incapacidade de tornar-se consciente de sua plena cidadania e das responsabilidades inerentes a ela. (...) Passar a lutar por tornar-se um indivíduo que não vive todo o tempo somente para si, ensimesmadamente, mas que assume sua condição de ser humano e sua responsabilidade enquanto cidadão, e engaja-se na luta por uma sociedade mais bem organizada e feliz, então é preciso reconhecer a seriedade desta vocação, é preciso compreender a complexidade da vida cultural do século XXI... quer queiramos, ou não, em cada atitude tomada e em cada discurso proferido, cada um de nós ajuda a definir o futuro de nosso ambiente sociocultural, de nossa cidade, de nosso país e de toda a humanidade (GOUVÊA, 2002, p.11-12).

A partir do pensamento de Gouvêa e da consciência da mutabilidade do conceito de cidadania, de acordo com o "espírito do tempo", chega-se à seguinte questão: Quais os direitos e deveres do cidadão típico do século XXI?

Se a inclusão digital é uma necessidade inerente desse século, então isso significa que o "cidadão" do século XXI, entre outras coisas, deve considerar esse novo fator de cidadania, que é a inclusão digital. E que constitui uma questão ética oferecer essa oportunidade a todos, ou seja, o indivíduo tem o direito à inclusão digital, e o incluído tem o dever de reconhecer que esse direito deve ser estendido a todos. Dessa forma, inclusão digital é um processo que deve levar o indivíduo à aprendizagem no uso das TICs e ao acesso à informação disponível nas redes, especialmente aquela que fará diferença para a sua vida e para a comunidade na qual está inserido.

Decorre daí um novo conceito que vem ganhando a forma de movimento mundial de bibliotecários, conscientes da necessidade de mudança na relação biblioteca-aprendizagem na sociedade contemporânea, que põe ênfase no acesso à informação nas redes. Surgido nos Estados Unidos, no início da década de 70, entre profissionais preocupados com o papel da biblioteca escolar na educação global, no novo "tempo digital", este conceito é denominado information literacy. Ele se desdobra em um outro, que lhe é correlato e complementar: o information literacy education, pelo qual se reconhece que information literacy é uma questão de educação para os tempos digitais ou, nos termos de Le Coadic (2004, p. 112), educação para a informação, o que será mais bem detalhado no próximo item.

Aqui, deve-se colocar em evidência que, por encontrarse a informação ou o conhecimento disponibilizado nas redes, "com a possibilidade de estar ao alcance de todos", a educação não está mais restrita aos espaços formais designados para essa função. Os que trabalham na perspectiva da inclusão digital, como organizações não-governamentais e associações de bairro, por exemplo, devem aproveitar a oportunidade para se constituírem em verdadeiros ambientes de educação. Que nos processos de inclusão digital contemplem essa educação para a informação, contribuindo para a formação de uma cultura informacional. No item a seguir, procura-se demonstrar a relação da inclusão digital com a educação para a informação.

\section{EDUCAÇÃO E INCLUSÃO DIGITAL}

Para tratar a relação entre a educação para a informação e inclusão digital, é preciso relembrar a exigência que provocou, no final do século XX, um movimento mundial: a inserção na sociedade da informação. Houve uma "corrida" para a construção de políticas nacionais, cujas propostas foram formuladas, em cada país, em vastos e abrangentes documentos governamentais.

O Brasil também empreendeu esse esforço de discussão, promovido pelo Ministério da Ciência e Tecnologia (MCT), que envolveu os quatro setores da sociedade governamental, privado, acadêmico, e o terceiro setor -, além de pessoas vinculadas a outros países e organizações internacionais. Isto se constituiu em verdadeiro desafio - em termos do estabelecimento do conteúdo e da necessidade de envolvimento de toda a sociedade brasileira - na construção de diretrizes para o estabelecimento 
de um programa que levasse a sociedade brasileira à entrada na sociedade da informação. $\mathrm{O}$ esforço resultou na publicação, em 2000, do Livro Verde da sociedade da informação (Socinfo) (Sociedade, 2000, p.xv).

Esse documento traz de forma muito clara, na proposta de universalização de serviços, que é necessário conceber soluções e promover ações que envolvam desde a ampliação e melhoria da infra-estrutura de acesso até a formação do cidadão, que, informado e consciente, possa utilizar os serviços disponíveis na rede.

Nesse sentido, a proposta de universalização de serviços, constante do Livro Verde, traz como inerente ao conceito de inclusão digital não só a aquisição de habilidades básicas para o uso de computadores e da Internet, mas também a capacitação para utilização dessas mídias, em favor dos interesses e necessidades individuais e comunitários, com responsabilidade e senso de cidadania. Essa ação é denominada, pelo Programa Socinfo, alfabetização digital.

No entanto, a Internet é um ambiente de informação complexo para quem não tem familiaridade ou capacitação na busca e recuperação da informação. Le Coadic (2004, p.112) lembra que

O montante de informação na Internet leva a que se proponham questões sobre as habilidades necessárias para aprender a se informar e aprender a informar, sobre onde adquirir a informação e chama a atenção de que essa aprendizagem é totalmente inexistente no sistema de ensino.

Então, para haver inclusão digital, é necessária a capacitação no acesso à informação na Internet, o que, conforme já se observou, é denominado, pelos programas governamentais, alfabetização digital. Essa expressão, que encerra o conceito certo, suscita, no entanto, controvérsias em um paralelo com o conceito de alfabetização.

Buzato (2003) destaca que pessoas alfabetizadas não são necessariamente "letradas". Mesmo sabendo "ler e escrever", isto é, codificar e decodificar mensagens escritas, muitas pessoas não aprenderam a construir uma argumentação, redigir um convite formal, interpretar um gráfico, encontrar um livro em um catálogo etc. A essa competência ele denomina letramento, que se constrói na prática social, e não na aprendizagem do código por si.

Assim, Buzato adota o termo letramento digital por entender que não se trata apenas de ensinar a pessoa a codificar e decodificar a escrita, ou mesmo usar teclados, interfaces gráficas e programas de computador, mas de inserir-se em práticas sociais nas quais a escrita, mediada por computadores e outros dispositivos eletrônicos, tem um papel significativo. Logo, letramento digital seria a habilidade para construir sentido, capacidade para localizar, filtrar e avaliar criticamente informação eletrônica, estando essa em palavras, elementos pictóricos, sonoros ou qualquer outro.

Parece haver uma tendência no entendimento de que alfabetização é a simples habilidade de reconhecer os símbolos do alfabeto e fazer as relações necessárias para a leitura e a escrita, o que encontra correspondente na alfabetização digital como aprendizagem para o uso da máquina. O letramento, contudo, é a competência em compreender, assimilar, reelaborar e chegar a um conhecimento que permita uma ação consciente, o que encontra correspondente no letramento digital: saber utilizar as TICs, saber acessar informações por meio delas, compreendê-las, utilizá-las e com isso mudar o estoque cognitivo e a consciência crítica e agir de forma positiva na vida pessoal e coletiva.

Dessa forma, fica claro que a inclusão digital não é uma simples questão que se resolve comprando computadores para a população de baixa renda e ensinando as pessoas a utilizar esse ou aquele software. Ter ou não acesso à infra-estrutura tecnológica é apenas um dos fatores que influenciam a inclusão/exclusão digital, mas não é o único, nem o mais relevante (BONILLA, 2001; SILVA, 2002).

Essa posição está em acordo com Tarapanoff, Suaiden e Oliveira (2002), que afirmam:

Não poderá haver sociedade da informação sem cultura informacional e que o maior problema da inclusão digital não é a falta de computadores, mas o analfabetismo em informação.

A alfabetização em informação deve criar aprendizes ao longo da vida, pessoas capazes de encontrar, avaliar e usar informação eficazmente, para resolver problemas ou tomar decisões. Uma pessoa alfabetizada em informação seria aquela capaz de identificar a necessidade de informação, organizá-la e aplicá-la na prática, integrando-a a um corpo de conhecimentos existentes e usando-a na solução de problemas.

Esse entendimento está inserido, também, no conceito de information literacy, que, como já destacado, surgiu na literatura de biblioteconomia, nos Estados Unidos, e vem se transformando em verdadeiro movimento mundial na área, de acordo com Belluzzo (2001; 2004), Dudziak (2002, p. 1-2), Virkus (2003, p. 2), Dudziak (2003, p.2324) e Campello (2003, p. 29). 


\section{Helena Silva / Othon Jambeiro / Jussara Lima / Marco Antônio Brandão}

O movimento tornou-se tão importante que, em 1989, foi criado nos Estados Unidos o National Fórum on Information Literacy, mantido pela American Library Association's Presidential Committee on Information Literacy. $O$ principal desafio desse fórum é a exclusão digital. Sua posição é a de que na sociedade da informação todas as pessoas têm direito ao acesso à informação, para melhoria da qualidade de vida.

O conceito, propagado pelo Fórum, disponível no site em 2004, é o da American Library Association (ALA), que assim conceitua information literacy:

Information Literacy is defined as the ability to know when there is a need for information, to be able to identify, locate, evaluate, and effectively use that information for the issue or problem at hand.

Ao traduzir essa conceituação da ALA, Dudziak (2003, p. 26) assim se expressa:

Para ser competente em informação, uma pessoa deve ser capaz de reconhecer quando uma informação é necessária e deve ter a habilidade de localizar, avaliar e usar efetivamente a informação. Resumindo, as pessoas competentes em informação são aquelas que aprenderam a aprender. Elas sabem como aprender, pois sabem como o conhecimento é organizado, como encontrar a informação e como usá-la de modo que outras pessoas aprendam a partir dela.

A Association for College and Research Libraries (2000) usa a mesma conceituação, acrescentando os valores de responsabilidade, ética e legalidade:

(...) é definida como a habilidade para reconhecer quando existe a necessidade de se buscar a informação, estar em condições de identificá-la, localizá-la e utilizá-la efetivamente para um objetivo específico e predeterminado - o desenvolvimento da sociedade com responsabilidade, ética e legalidade. Também denominada de alfabetização do século XXI (Belluzzo, 2001, p. 3).

Em artigo de revisão sobre o conceito na Europa, Virkus (2003) ressalta que o maior volume de literatura sobre o assunto se encontra nos Estados Unidos e Austrália, exatamente porque foi lá que começou a discussão. Ele examina o desenvolvimento da competência informacional na Europa, oferecendo uma visão geral, a partir da revisão da literatura e de observações pessoais, sobre o conceito e as discussões de vários autores europeus. Relaciona alguns exemplos de iniciativas em escolas e na educação superior; instituições e organizações que trabalham o conceito; projetos e conferências. É uma boa visão do ponto de vista europeu.

Para começar, Virkus (2003, p.2) utiliza-se de uma citação de Bruce (2002), que parece sintetizar o entendimento do conceito:

A idéia de information literacy emerge com o advento das TICs no início dos anos 70 e vem crescendo com força o reconhecimento de que é uma competência crítica no século XXI. Algumas vezes interpretada como mais uma de várias competências, ela é descrita também como a competência mais essencial para o século XXI e está, atualmente, intrinsecamente associada com práticas de informação e o pensamento crítico, no ambiente das tecnologias de informação e comunicação" (Bruce, 2002, apud Virkus, 2003, p.2.) (tradução nossa).

Campello (2003) ressalta que o início do movimento foi uma reação de bibliotecários, no sentido de adotar uma posição proativa da biblioteca, em relação à crescente demanda por mudanças para inserção na sociedade da informação. Os bibliotecários compreenderam que para isso é necessário mais do que a visão ingênua e simplista do processo de busca e uso da informação. Este relato parece estar de acordo com a declaração de Bruce, citada no parágrafo anterior.

Virkus (2003,p. 2-3.3) aponta que o Departamento de Educação dos Estados Unidos incluiu information literacy no seu plano nacional de educação em tecnologia, como objetivo, desde 2000. Ele mostra ações em alguns estados e universidades desse país como programas de information literacy. Além disso, a Austrália e vários outros países vêm fortalecendo a aplicação do conceito como estratégico. O mesmo autor (2003, p.10) aprofunda a análise e destaca que o movimento, o conceito e as ações são semelhantes aos de países fora da Europa.

No Brasil, o movimento está apenas começando e não há consenso quanto à tradução para o português. Belluzzo (2001; 2004) e Dudziak (2002; 2003) preferem usar a expressão sem tradução. Campello (2002; 2003) a traduz para competência informacional. Os artigos dessas autoras oferecem uma visão abrangente do desenvolvimento do conceito.

No entanto, a idéia de information literacy leva à consideração da information literacy education, ou a educação para a informação, como observam Dudziak (2002) e Le Coadic (2004, p.112). Para que as pessoas 
adquiram information literacy, é preciso que a educação insira esse aprendizado nos seus currículos. Information literacy é uma questão de educação.

Le Coadic (2003, p.113) frisa que muitas pessoas são pesquisadoras medíocres de informação. Que a introdução no ensino da disciplina 'informação', com um quadro de professores especializados, seria a garantia para o ingresso dos alunos na sociedade da informação.

Depois de desenvolvido no ambiente escolar, o conceito sobre as relações dos bibliotecários e professores, ganhou portanto, impulso, passando a ser considerado no ambiente acadêmico. Moore (2002, p.5) faz uma análise da information literacy education no mundo e a coloca como uma aplicação compulsória na educação para enfrentar o desafio da exclusão digital.

$\mathrm{Na}$ verdade, esse conceito parece apropriado para elucidar a capacidade necessária do indivíduo com relação à informação. Ele traz, desde sua origem, uma aproximação muito nítida com a questão da cidadania e com as habilidades ligadas ao uso da informação em meio eletrônico. Hamelink e Owens (1976), citados por Dudziak (2003), afirmam que os cidadãos competentes no uso da informação estão em posição de tomar decisões mais inteligentes e socialmente responsáveis que os cidadãos que não estão bem informados.

É, pois, possível concluir-se que educação para a informação deveria se constituir em uma política pública para inclusão digital, em qualquer meio ou organização que se proponha a este tipo de ação, como, por exemplo, as organizações não-governamentais.

\section{SÍNTESE CONCEITUAL}

Chega-se ao final com a certeza de que inclusão digital encerra um complexo inter-relacionamento de conceitos e tem como ponto central a educação para a informação ou information literacy education. Nesse sentido, a relação entre inclusão digital e educação para a informação (information literacy education) constitui objeto de pesquisa emergente e importante para a ciência da informação. Como uma ciência social aplicada e em acordo com as mudanças ocorridas na sociedade contemporânea, a ciência da informação tem enorme papel econômico e social. Freire (2002, p.11) defende que:

(...) mais que organizar e processar conhecimento científico, como antes dos primórdios da ciência da informação, será importante prover seu acesso público através das mais diversas formas e dos mais diversos canais de comunicação, de maneira que essa nova força de produção social possa estar ao alcance dos seus usuários potenciais.

Esse posicionamento atual da ciência da informação, como facilitadora da comunicação do conhecimento, principalmente em países em desenvolvimento como o Brasil, é indispensável quando se defronta com a realidade: o que está a definir o aumento ou redução da desigualdade social é justamente o nível de utilização do conhecimento e sua aplicação, hoje, de forma inalienável, via TICs.

A educação para a informação está, portanto, no cerne de uma nova e desejada sociedade "incluída", que seja amparada na consideração "cuidadosa" de uma educação que envolva novas e ousadas abordagens relacionadas ao acesso à informação por meio das TICs.

Artigo, recebido em 07/12/2004 e aceito para publicação em 15/08/2005. 


\section{Helena Silva / Othon Jambeiro / Jussara Lima / Marco Antônio Brandão}

\section{REFERÊNCIAS}

ARAÚJO, E. A. Informação, sociedade e cidadania: gestão da informação no contexto de organizações não-governamentais (ONGs) brasileiras. Ciência da Informação, Brasília, v. 28, n. 2, p. 155-167, maio/ago. 1999.

BARreto, A. A. A questão da informação. São Paulo em Perspectiva, São Paulo, v. 8, n. 4, p. 3-8, 1994. Disponível em:

<http://www.alternex.com.br/ aldoibict/quest/quest.htm>.

Acesso em 26 fev. 2004.

BELLUZZO, R.C.B. A information literacy como competência necessária à fluência científica e tecnológica na Sociedade da Informação: uma questão de educação. In: SIMPÓSIO DE ENGENHARIA DE PRODUÇÃO DA UNESP, 7., 2001, Bauru. Anais eletrônicos... Bauru: UNESP, 2001. Disponível em:

< http://www.simpep.feb.unesp.br/anais8/ana8c.html\#GI >.

Acesso em: 12 mar. 2004.

. Formação contínua de professores do ensino fundamental sob a ótica do desenvolvimento da information literacy, competência indispensável ao acesso à informação e geração do conhecimento. Transinformação, Campinas, v. 16, n. 1, p. 17-32, jan./abr. 2004.

BOBBIO, Norberto. O futuro da democracia: uma defesa das regras do jogo. Rio de Janeiro: Paz e Terra, 1986.

BODSTEIN, R. A. Cidadania e modernidade: emergência da questão social na agenda pública. Cadernos de Saúde Pública, Rio de Janeiro, v. 13, n. 2, abr./jun. 1997.

BONILLA, Maria Helena. O Brasil e a alfabetização digital. Jornal da Ciência, Rio de Janeiro, p. 7, 13 abr. 2001. Disponível em:

< http:// www.faced.ufba.br/ bonilla/artigojc.htm>.

Acesso em: 12 mar. 2004.

BUZATO, Marcelo E. K. Letramento digital abre portas para o conhecimento. EducaRede, 11 mar. 2003. Disponível em:

http://www.educarede.org.br/educa/html/index_busca.cfm>.

Acesso em: 12 mar. 2004.

CAMPELO, Bernadete. O movimento da competência informacional: uma perspectiva para o letramento informacional. Ciência da informação, Brasília, v. 32, n. 3, p. 28-37, set./dez. 2003.

CANIELLO, M. O ethos sanjoanense: tradição e mudança em uma cidade pequena. Mana: estudo de antropologia social, v. 9, n. 1, p. 31-56, 2003.

DUDZIAK, Elisabeth Adriana. Information literacy: princípios, filosofia e prática. Ciência da Informação, Brasília, v. 32, n. 1, p. 23-35, jan./abr. 2003.

. Information literacy education: integração pedagógica entre bibliotecários e docentes, visando a competência em informação e o aprendizado ao longo da vida. In: SEMINARIO NACIONAL DE BIBLIOTECAS UNIVERSITÁRIAS, 12., Recife, 2002. Anais... Recife: UFPE, 2002. 1 CD-ROM.

FRADE, Marco Antônio Fernandes. Mídia e cidadania. Revista Informação E Sociedade: estudos, João Pessoa, v. 12, n. 1, 2002. Disponível em: $<$ http://www.informacaoesociedade.ufpb.br/1210201.pdf>.

Acesso em: 25 jul. 2004.

FREIRE, Isa Maria. Da construção do conhecimento científico à responsabilidade social da ciência da informação. Informação Eु Sociedade, João Pessoa, v. 12, n. 1, 2002.

GOUVÊA, Ricardo Quadros. Ética e cidadania: a busca humana por valores humanos. In: UM OLHAR sobre cidadania. São Paulo: Mackenzie, 2002. p. 9-30. (Coleção Reflexão Acadêmica).

HACK, Osvaldo H. Apresentação. In: UM OLHAR sobre cidadania. São Paulo: Mackenzie, 2002. p. 7. (Coleção Reflexão Acadêmica).

LASTORIA, Luiz. A. C. Nabuco. Ethos sem ética: a perspectiva crítica de T.W. Adorno e M. Horkheimer. Educação e Sociedade, v. 22, n. 76, out. 2001.

LE COADIC, Yves-François. A ciência da informação. Brasília: Briquet de Lemos, 2004.

MOORE, Penny. An analysis of information literacy education worldwide. July, 2002. White paper prepared for UNESCO, the U.S. National Commission on Libraries and Information Science, and the National Forum on Information Literacy, for use at the Information Literacy Meeting of Experts, Prague. Disponível em:

$<$ www.nclis.gov./libinter/infolitconf\&meet/moore-fullpaper.pdf $>$. Acesso em: 15 mar. 2004.

NATIONAL FORUM ON INFORMATION LITERACY. Disponível em: $<$ http://www.infolit.org/>.

Acesso em: 2005.

PIRES, Hindenburgo F. Ethos e mitos do pensamento único global totalitário. Terra Livre, São Paulo, n. 16, p. 153-167, 2001.

ROCHA, Marisa Perrone Campos. A questão cidadania na sociedade da informação. Ciência da Informação, Brasília, v. 29, n. 1, p. 40-45, jan./ abr. 2000.

RONCA, A. C. C.; COSTA, R. A construção de uma democracia cognitiva. São Paulo em Perspectiva, São Paulo, v. 16, n. 4, p. 24-29, 2002.

SILVA, J. B. G. Alfabetização tecnológica: alguns aspectos práticos. Boletim EAD, Campinas, n. 41, 2002. Disponível em: $<$ http://www.ead.unicamp.br/php_ead/boletim.php>. Acesso em: 22 fev. 2003.

SILVA, R. H. A.; MEIRA, W. Rede de Inclusão e Letramento Digital - Rede. Lê. In: CONGRESSO BRASILEIRO DE EXTENSÃO UNIVERSITÁRIA, 2., 2004, Belo Horizonte. Anais eletrônicos... Belo Horizonte: [s.n.], 2004. Disponível em: <http://www.ufmg.br/congrext/Tecno/Tecno10.pdf >. Acesso em: 10 nov. 2004.

SILVEIRA, H. F. R. Um estudo do poder na sociedade da informação. Ciência da Informação, Brasília, v. 29, n. 3, p. 79-90, set./dez. 2000.

SOUZA NETO, J. Clemente de; LIBERAL, M. M. Costa de. Apontamentos para uma compreensão da ética na dinâmica das transformações sociais. In: UM OLHAR sobre cidadania. São Paulo: Mackenzie, 2002. p. 31-52. (Coleção Reflexão Acadêmica).

TAKAHASHI, Tadao (Org.). Sociedade da informação no Brasil: livro verde. Brasília: Ministério da Ciência e Tecnologia, 2000.

TARAPANOFF, Kira; SUAIDEN, Emir; OLIVEIRA, Cecília Leite. Funções sociais e oportunidades para profissionais da informação. DataGramaZero - Revista de Ciência da Informação, v. 3, n. 5, out. 2002. Disponível em: < http://www.dgz.org.br/out02/Art_04.htm>.

Acesso em: 2 ago. 2004.

VIRKUS, S. Information literacy in Europe: a literature review. Information Research, v. 8, n. 4, 2003. Disponível em:

$<$ http://informationr.net/ir/8-4/paper159.html>.

Acesso em: 2005. 